\title{
Simulation on the Supporting of Underground Storage Foundation Pit by Anchor and Soil Nail
}

\author{
Yong Feng \\ School of Civil Engineering, Henan University of Technology, Zhengzhou, Henan, \\ China, 450001,E-mail:51433719@qq.com
}

\begin{abstract}
At present, the composite supporting technology of prestressed anchor and soil nailing has been more and more widely used in the foundation pit engineering, but the related existing theory and method can not satisfy the engineering practice, so it is necessary to do the discussion of this technology. In this paper, the foundation pit of underground storage in Zheng Zhou City was chose as an example, the simulation model for composite supporting of anchor and soil nail was set by FLAC software, the ideal elastic-plastic constitutive model was selected for soil, the cable unit was selected for the prestressed anchor and soil nailing, based on the interaction between supporting system and soil, the dynamic process for the excavation and support of foundation pit was simulated. The law for the effect of the excavation on disturbance, soil changes in displacement and internal force distribution of soil nail and anchor was obtained in this study, the connection line of the maximum axial force of soil nail and anchor were actually the potential failure surface of soil foundation pit, the position change of maximum axial force reflected the trends of internal displacement of excavated soil. The related conclusions have certain reference significance for the composite anchor and soil nailing supporting design.
\end{abstract}

Key words: underground storage foundation pit; anchor; soil nail; FLAC

\section{Introduction}

In recent years, the deep foundation pit engineering has become a significant position in the civil engineering, then the corresponding foundation pit supporting problem has become one of the hot issues in building engineering [1]. For the supporting of anchor and soil nail, because it has the advantages such as advanced technology, economic feasibility, reliable quality, quick construction and adjustment during the process of dynamic construction, so it has been widely used in the foundation pit engineering. Besides, for the composite supporting by anchor and soilnail, the anchor and soilnail can restrict the displacement of foundation pit slope effectively, so it can control the deformation of pit well [2].

At present, the composite supporting technology of prestressed anchor and soil nailing has been more and more widely used in the foundation pit engineering, but the related existing theory and method can not satisfy the engineering practice, so it is necessary to do the discussion of this technology. Because the traditional design method of foundation pit supporting is difficult to consider the interaction between rock mass and support system and the nonlinear of excavation process, therefore, the numerical simulation method become a viable option.

In this paper, the foundation pit of underground storage in Zheng Zhou City was chose as an example, the simulation model for composite supporting of anchor and soil nail was set by FLAC software in order to better understanding of its mechanism, so it can provide a beneficial reference for the design and construction of this composite supporting mode. 


\section{Project Summary and Supporting Design}

\subsection{Project Summary}

The foundation pit of underground storage locates in the Zhongmou county, zhengzhou city, the plane shape is a rectangle, the size of the foundation pit is $100 \times 80 \mathrm{~m}^{2}$, the depth of it is $11.5 \mathrm{~m}$. The importance of foundation pit is first class (China standard). Based on the survey data, the top-down stratum situation of this site is shown in the following Table 1.

Table 1. Soil Mechanics Parameters

\begin{tabular}{lllllll}
\hline Name & $\begin{array}{l}\text { Thickness } \\
/ \mathrm{m}\end{array}$ & $\begin{array}{l}\text { Severe } \\
/ \mathrm{kN} \cdot \mathrm{m}-3\end{array}$ & $\begin{array}{l}\text { Cohesive } \\
\text { force } / \\
\mathrm{kPa}\end{array}$ & $\begin{array}{l}\text { Angle } \\
\text { internal } \\
\text { friction } /^{\circ}\end{array}$ & $\begin{array}{l}\text { of } \\
\text { on } \\
\text { modulus } \\
/ \text { Mpa }\end{array}$ & $\begin{array}{l}\text { ratio } \\
\text { ration's }\end{array}$ \\
\hline Miscellaneous fill & $0.8 \sim 1.5$ & 17.5 & 13 & 16 & 9 & 0.4 \\
Clayey silt & $6.5 \sim 7.2$ & 18.9 & 20 & 21 & 18 & 0.33 \\
Sandy silt & $0.5 \sim 1.5$ & 19 & 22 & 23 & 18 & 0.33 \\
Silty clay & $>9$ & 19.5 & 20 & 22 & 18 & 0.33 \\
\hline
\end{tabular}

\subsection{Design for the Supporting of Foundation Pit}

According to the geological report and surrounding environment conditions, the composite plan of prestressed anchor, grouting soil nail and shotcrete layer was chose in this supporting ,the related supporting parameters were determined by calculation analysis and engineering analogy method.

The excavation of foundation pit is divided into 9 steps, the first step is $1 \mathrm{~m}$, step 2 to step 6 is $1.5 \mathrm{~m}$ and step 7 to step 9 is $1 \mathrm{~m}$. For the step 2 and step 5, the anchor supporting was chose, the other steps were supported by soil nail, total 7 row of soil nails and 2 row of prestressed anchors were designed, the related profile for supporting foudantion pit is shown in the following Figure 1.

For the prestressed anchor, it adopts the screw-thread steel pipe which is $2 \mathrm{~mm}$ in diameter, the prestressing force is $150 \mathrm{kN}$, it is 15 to $17 \mathrm{~m}$ in length, the angle is $10^{\circ}$ and the horizontal spacing is $1.3 \mathrm{~m}$, the vertical spacing is shown in the following Figure 1. The first row of bolt is set at $2.5 \mathrm{~m}$ below the surface, the second row of bolt is set at $7 \mathrm{~m}$ below the surface.

For the soil nail, it adopt the HRB335 hot rolled ribbed bar which is $25 \mathrm{~mm}$ in diameter, it is 6 to $11 \mathrm{~m}$ in length, the angle is $10^{\circ}$ and the horizontal spacing is also $1.3 \mathrm{~m}$, the vertical spacing is from 1.0 to $1.5 \mathrm{~m}$. The distance between the first row of soil nail and top of foundation pit is $1 \mathrm{~m}$. The foundation pit side wall layer adopts steel fabric shotcrete.

\section{Simulation Analysis}

For this composite supporting of anchor and soil nail, the common mechanical model can not analyze the interaction between anchor ( or soil nail) and soil and rock, but the interaction is complicated, the assumed model often can not reflect the actual situation. The numerical simulation can analyze the variation law of rock and soil excavation from the macro overall trend. For many numerical methods, FLAC (Fast Lagrangian Analysis of Continua) is suitable to the most engineering mechanics problems, it can well simulate the mechanical behavior of damage or plastic flow of geotechnical material when the strength limit and yield limit are reached, therefore, the FLAC software was adopted in 
this simulation for this simulation.

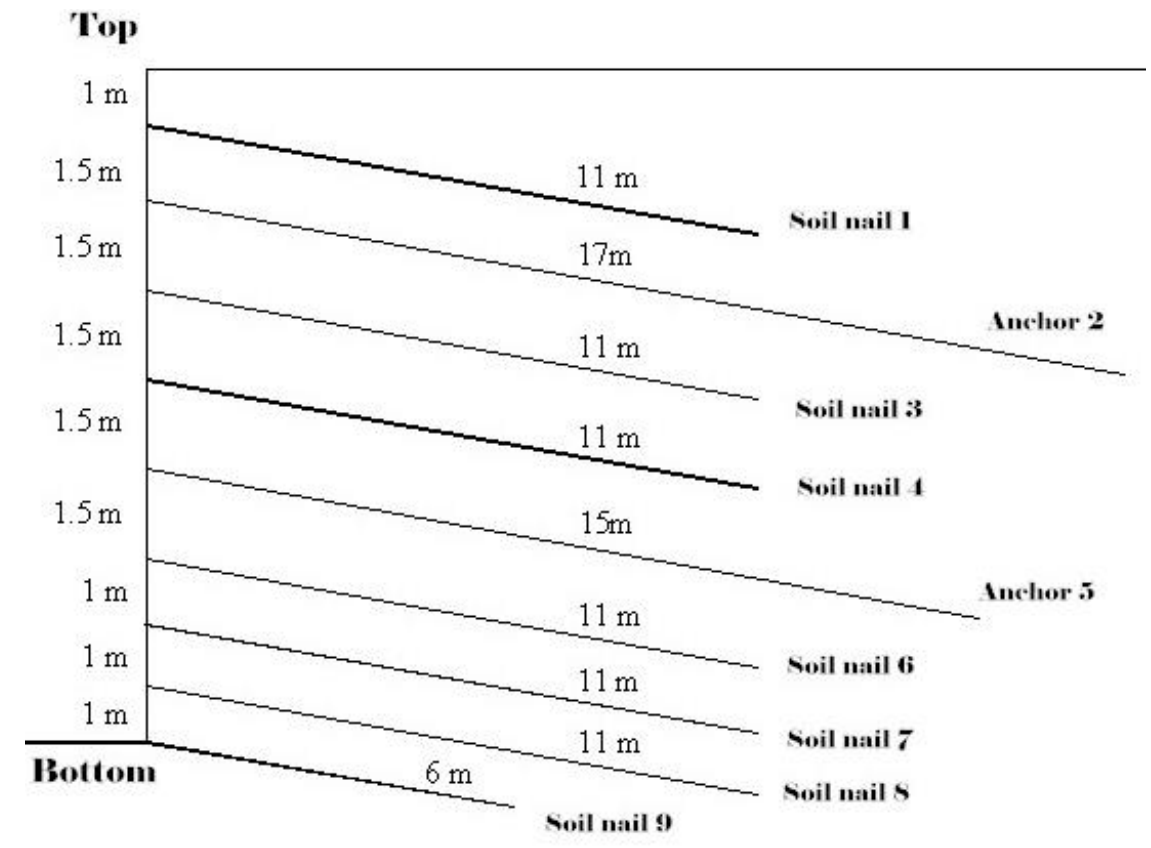

Figure 1. Profile for Supporting Foudantion Pit by Prestressed Anchor Arm and Soil Nail

\subsection{Basic Assumptions}

In order to set the model easily, based on the actual situation supporting of the excavation, the following assumptions were set [3]: (1) The supporting structure is a plane strain problem. (2) For highlighting of the anchor and soil nailing pit reinforcement effect, the reinforcement of concrete sprayed layer is not considered in this simulation, an appropriate increment in soil nail and filling body will be set to offset the ignored error produced by sprayed layer. (3) Anchor, soil nail, surrounding soil and slurry are completely bonded, it can satisfy the deformation compatibility condition. (4) For this simulation, because the precipitation is full, the impact of groundwater can not be considered.

\subsection{Soil Constitutive Model Selection and Related Parameters}

In this simulation, the body of soil and rock adopted the ideal elastic-plastic model and the yield criterion used Mohr - Coulomb criterion.

The deformation parameters for the body of rock and soil adopt shear modulus $G$ and bulk modulus $\mathrm{K}$. For the specific calculation, the $\mathrm{G}$ and $\mathrm{K}$ can be obtained by the following Equation (1) and deformation modulus $\mathrm{E}_{0}$ [4].

$$
K=\frac{E_{0}}{3(1-2 \mu)}, G=\frac{E_{0}}{2(1+\mu)}
$$

\subsection{Supporting Structural Units for the Simulation}

FLAC can be used for simulating the mechanism of anchor or soil nail successfully, in this method, the cable structure is an ideal one-dimensional elastic-plastic unit which can only withstand tensile and compressive stresses and can not afford bending moment[4]. For this simulation model, the cable structure was used. 


\subsection{Creation of Numerical Analysis Model}

The two-dimensional model was extended to three-dimensional model along per unit width, the FLAC3D was used to do the simulation.

(1) Based on the requirements of constructing model, the impacting depth of $x$ direction (the horizontal direction) adopted 3 to 4 times of that of excavation and the impacting depth of y direction (the vertical direction) adopted 1 to 2 times of that of foundation pit excavation. For this model, the total length in the $\mathrm{x}$ direction is $90 \mathrm{~m}$, the total length in the y direction is $30 \mathrm{~m}$, the excavation range which is total $11.5 \mathrm{~m}$ is divided to 9 groups to simulate the excavation of foundation pit. Foe the $\mathrm{z}$ direction, the unit width is used and the interaction between supporting structure can be ignored.

(2) Set the initial and boundary conditions. The ground boundary is regarded to be stationary and fixed hinged is used. The vertical direction is not limited which can slide freely.

(3) Elastic-plastic model is chose, then the gravity stress field is applied to the soil, make the soil to reach equilibrium in the initial conditions, then the displacement is cleared. Then the model can reach equilibrium under building load.

(4) For the excavation step, the excavated soil is replaced with null model, then the supporting structure (cable unit) is added, the unbalanced force could be eliminated by iterative approach and the internal forces of supporting structure is obtained.

(5) Repeat the previous step, do the stepwise excavation until to the pit bottom.

The model is shown in the following Figure 2. It has a total of 29,490 units and 42,253 nodes. The soil parameters were chose as the Table 1 above. The soil nail reinforcement (HRB335) modulus takes $200 \times 10^{6} \mathrm{kPa}$, the cement modulus takes $20 \times 10^{6} \mathrm{kP}$ a and the soil nail adhesive strength takes $50 \mathrm{kP}$ a. The prestressed anchor strand modulus takes 180 $\times 10^{6} \mathrm{kPa}$, the cement mortar modulus take $20 \times 10^{6} \mathrm{kPa}$ and the soil nail adhesive strength to takes $50 \mathrm{kPa}$.

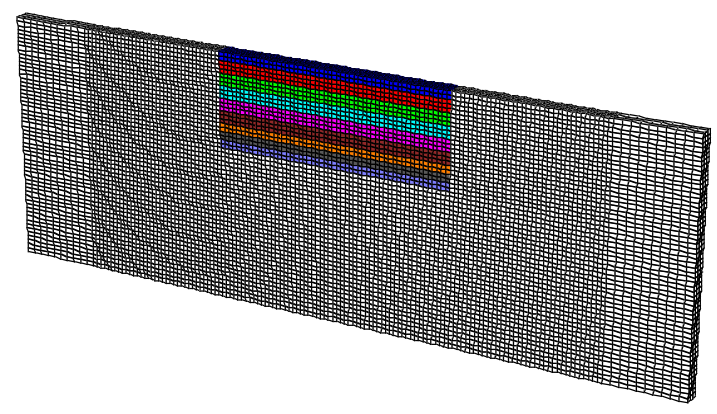

Figure 2. Mesh for Computation Model

\section{Calculation Results}

As mentioned above, excavation is performed to 9 steps, the supporting is made immediately after the excavation is complete, the simulation is made based on actual construction sequence.

\subsection{Unbalanced Force Analysis}

The relationship between maximum unbalanced force and calculation step during the excavation is shown in the following Figure 3. 


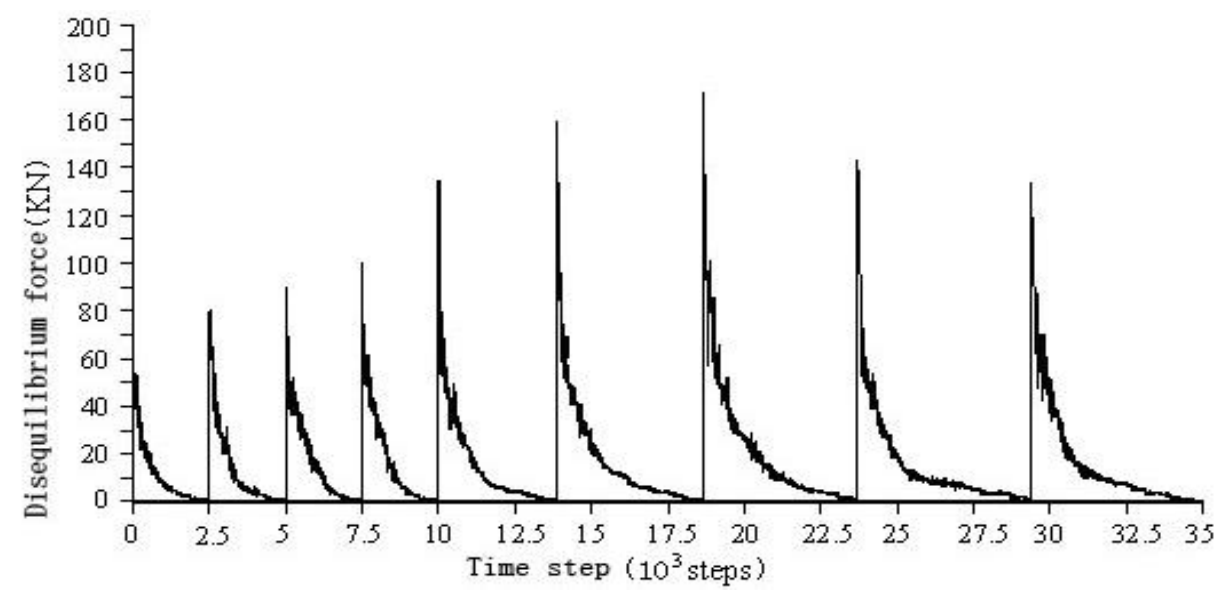

Figure 3. Disequilibrium Force for Computation

According to the Figure 3, after each excavation, the unbalanced force of system increases rapidly and then a peak will appears. Then, because the effect of the anchor and soil nail, the unbalanced force has come down quickly and eventually reduces to a very low range and to be stabilized. Every excavation have caused a disturbance of the soil, so the model change from the balance state to the imbalance state, with the passage of time, the unbalanced force is dissipating into the soil and finally become balance. For this simulation, it was found that the unbalanced force of step5,step 6 and step7 (5.5m to $9.5 \mathrm{~m}$ deep ) was more than that of other steps, so the step5,step 6 and step7 had great effect on the stability of foundation pit, which should be fully paid attention to.

\subsection{The Horizontal Displacement of Foundation Pit}

In order to monitor the horizontal displacement of foundation pit, 10 monitoring points are set along the foundation pit side wall, at the same time, 10 monitoring stations which are $8 \mathrm{~m}$ distant to the foundation pit side are along set along the vertical direction, all the 20 monitoring pints are shown in the following Figure 4, the History command is used to monitor the displacement of them, the horizontal displacement of the points after excavation is shown in the following Figure 5.

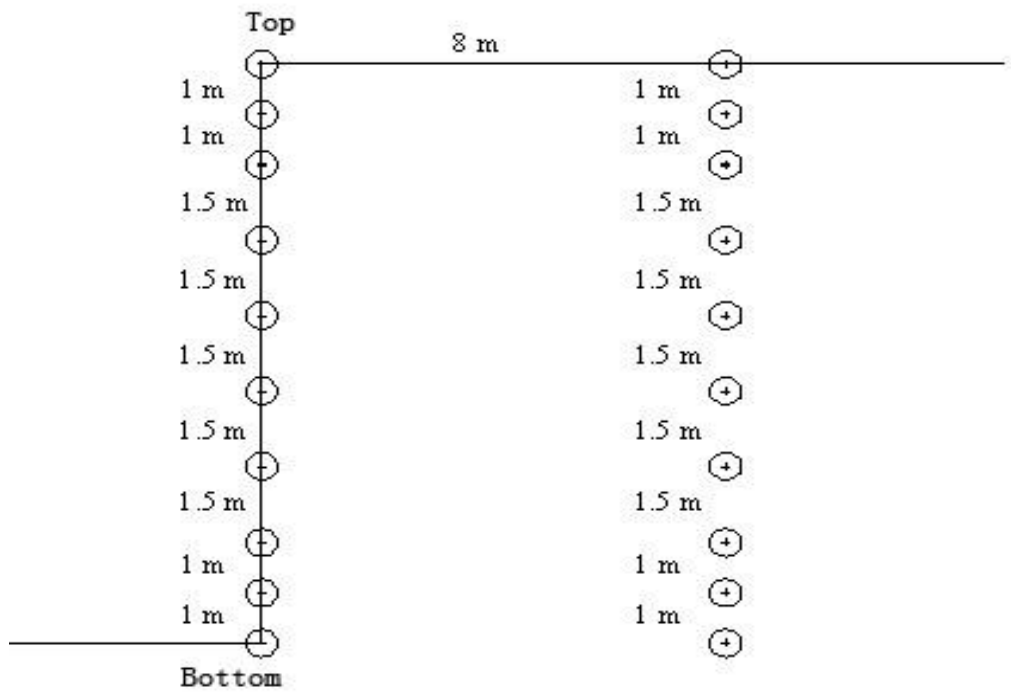

Figure 4. Allocation for Level Displacement Monitor Points 


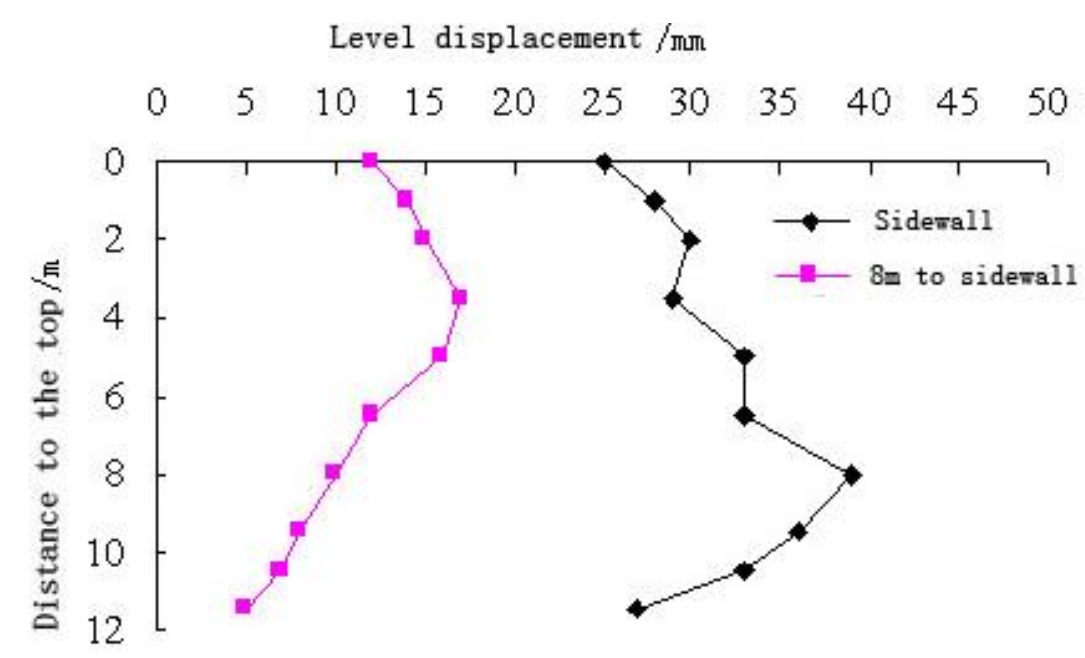

Figure 5. Level Displacement of Foundation Pit

According to Figure 5, the following conclusion could be obtained. (1) For the soil foundation pit, the maximum horizontal displacement generally appeared at the edge of the foundation pit wall surface, the internal horizontal displacement which was away from the side wall was relatively small. (2) The value of upper horizontal displacement of the pit side wall was smaller, the horizontal displacement of medium-bottom pit side wall was lager, the lateral deformation was in the shape of drum. The maximum displacement was $39 \mathrm{~mm}$, which located in the $8 \mathrm{~m}$ to the pit top. Therefore, this location is the important part for the deformation of foundation pit and the horizontal displacement development should be paid attention to during the construction.

In order to verify the correctness of the numerical simulation results, the simulated results and were compared with the measured results, the curves of them were almost the same, the actual measured maximum horizontal displacement of foundation pit side wall was $33 \mathrm{~mm}$ and the calculated value is $18.2 \%$ larger than the measured values.

\subsection{The Vertical Displacement of Foundation Pit}

In order to monitor the vertical displacement of foundation pit, 10 monitoring points are set on the top of foundation pit, at the same time, 10 monitoring points which are $5 \mathrm{~m}$ to the foundation pit top are also set along the horizontal direction, the location of all the total 20 monitoring points are shown in the following Figure 6, the History command is used to monitor the displacement of them, the vertical displacement of the points after excavation is shown in the following Figure 7.

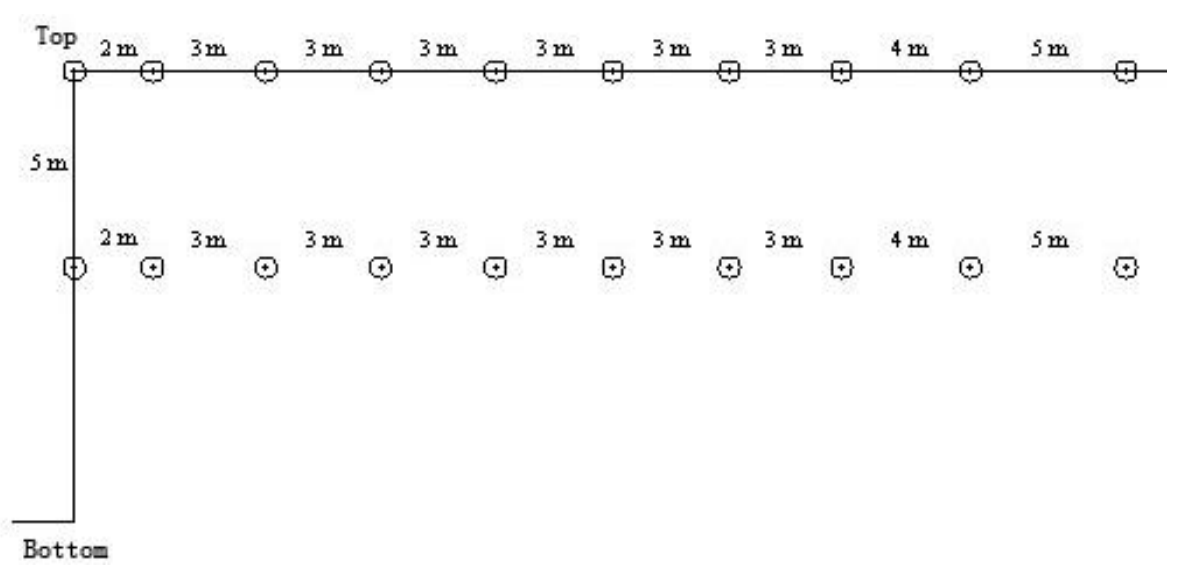

Figure 6. Allocation for Vertical Displacement Monitor Points 


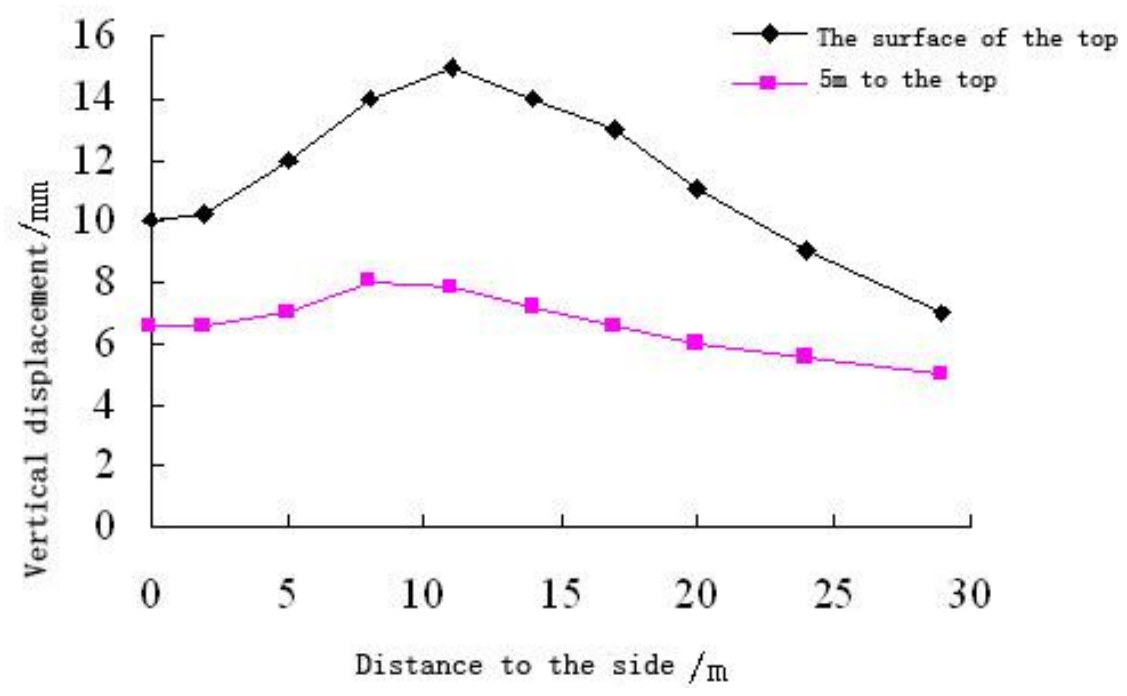

Figure 7. Vertical Displacement of Foundation Pit

According to Figure 7, the following conclusion could be obtained. (1) The vertical displacement when the excavation is completed decreased with the increment of depth. (2) The vertical displacement below the center of additional load was the largest and that of both sides was smaller. The maximum vertical displacement of the foundation pit surface is $15.3 \mathrm{~mm}$, which was $11 \mathrm{~m}$ to the foundation side.

At the same time, in order to verify the correctness of the numerical simulation results, the simulated results and were compared with the measured results, the curves of them were almost the same, the actual measured maximum vertical displacement of foundation pit surface was $17.6 \mathrm{~mm}$ and the calculated value is $13.1 \%$ less than the measured values.

\subsection{Axial Force Analysis for Anchor and Soil Nail}

(A) According to the work mechanism analysis of the soil nail, the point of maximum soil nail axial force located at the sliding surface, its biggest axis point is along the point changing along the direction of shearing force. Therefore, the distribution law of maximum axial force should be focused, According to the numerical calculation, the distribution of axial force along the length was shown in the following Figure 8. Based on Figure 8 , it was found that for the same soil nail, the internal force was not balanced and the axial force of soil nail (pulling force) changed along its length. Upper soil nailing (soil nailing 1 and 3) axial force was generally characterized by the law of larger in the middle and smaller on both sides, which is in the shape of a handful. Besides, with the depth increasing of soil nail, the location of the maximum soil nail axial force changed, the axial force of end was the largest and decreased along the direction of soil nail to the soil body, which was in the shape of parabolic distribution (soil nail 4, 6, and 8).

For the vertical direction of in foundation pit, the position for the maximum axial force of each row of soil nail moved to the surface (foundation pit side), the maximum axial force value of the upper first row of soil nail located in the medium-back of soil nail (away from the foundation pit side wall), but the maximum axial force value of the last row of soil nail appeared in a place close to the foundation pit side wall. Based on the maximum value of axial force and the related data of location, then the connection of the maximum axial force were obtained, which was shown in the following Figure 9. 


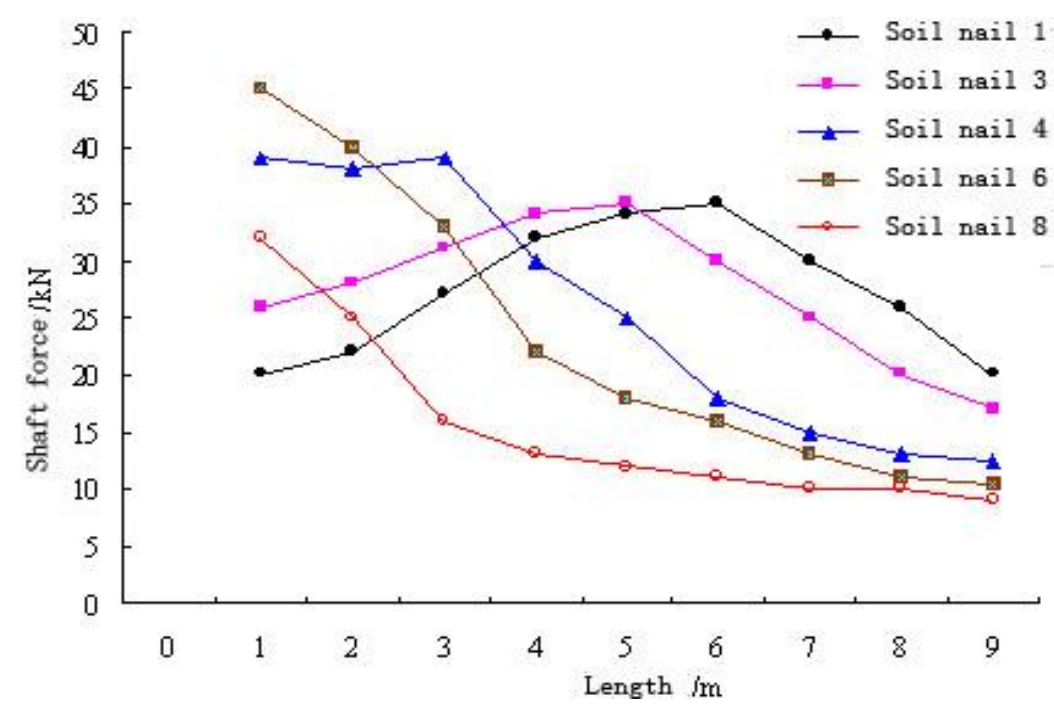

Figure 8. Shaft Force Distribution for Brad

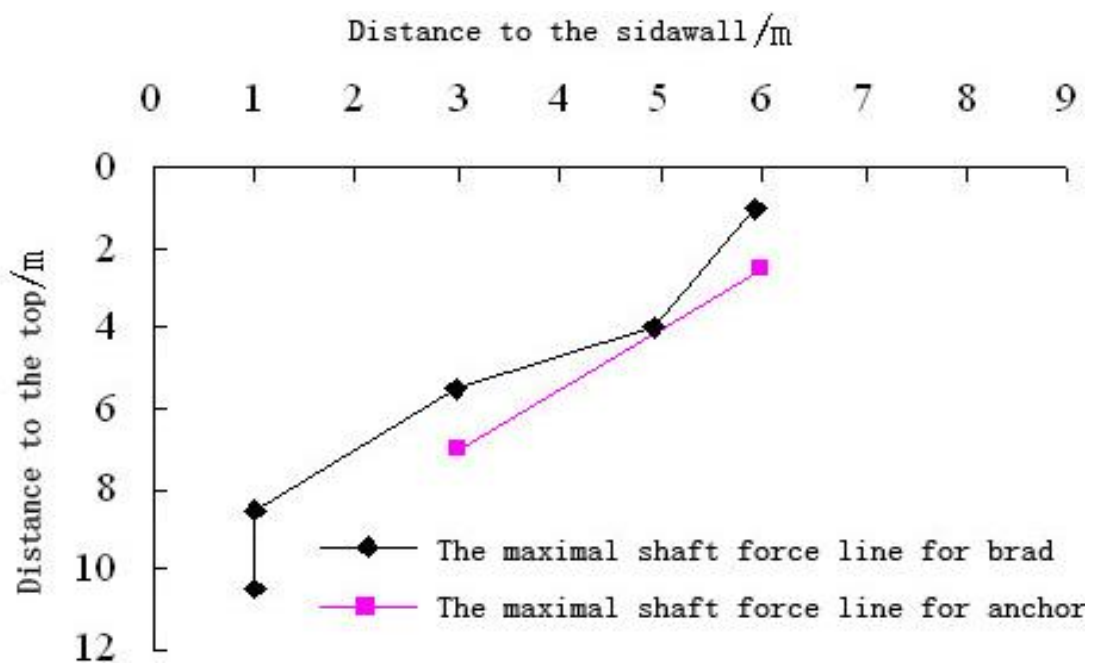

Figure 9. The Maximal Shaft Force Line for Brad and Anchor

The law for the location change of maximum axial force was the reflection of soil nailing anchorage performance, according to the related soil damage theory, the connection line of the maximum axial force of each row of soil nails was actually the potential failure surface of soil foundation pit (sliding surface of minimum safety coefficient), the change of maximum axial force position reflected the change and development trend of foundation pit soil. The trend of attachment of axial force maximum was appropriately extended and it intersected with the foundation pit side wall in the depth of 8 9m, which was the possible damage location. The related conclusions above are basically the same as that of Figure 5 above.

(B) According to Figure 8, for the soil nails of different depth, there was a difference of maximum axial force of them. The top and bottom of the soil nail force was relatively small, which caused the force of soil nails in the middle of pit slope larger. The maximum axial force of soil nail $6(8.5 \mathrm{~m}$ deep) was significantly greater than that of that of soil nails, it reflected the deformation of the soil here was lager, the excavation of this range will have great effect on the stability of foundation pit.

(C) For the prestressed anchor, the maximum axial force appeared in the free section and was the same for all the free section. The axial force decreased along the anchoring 
segment and the end of the axial force was very small (almost zero), which was shown in the following Figure 10.

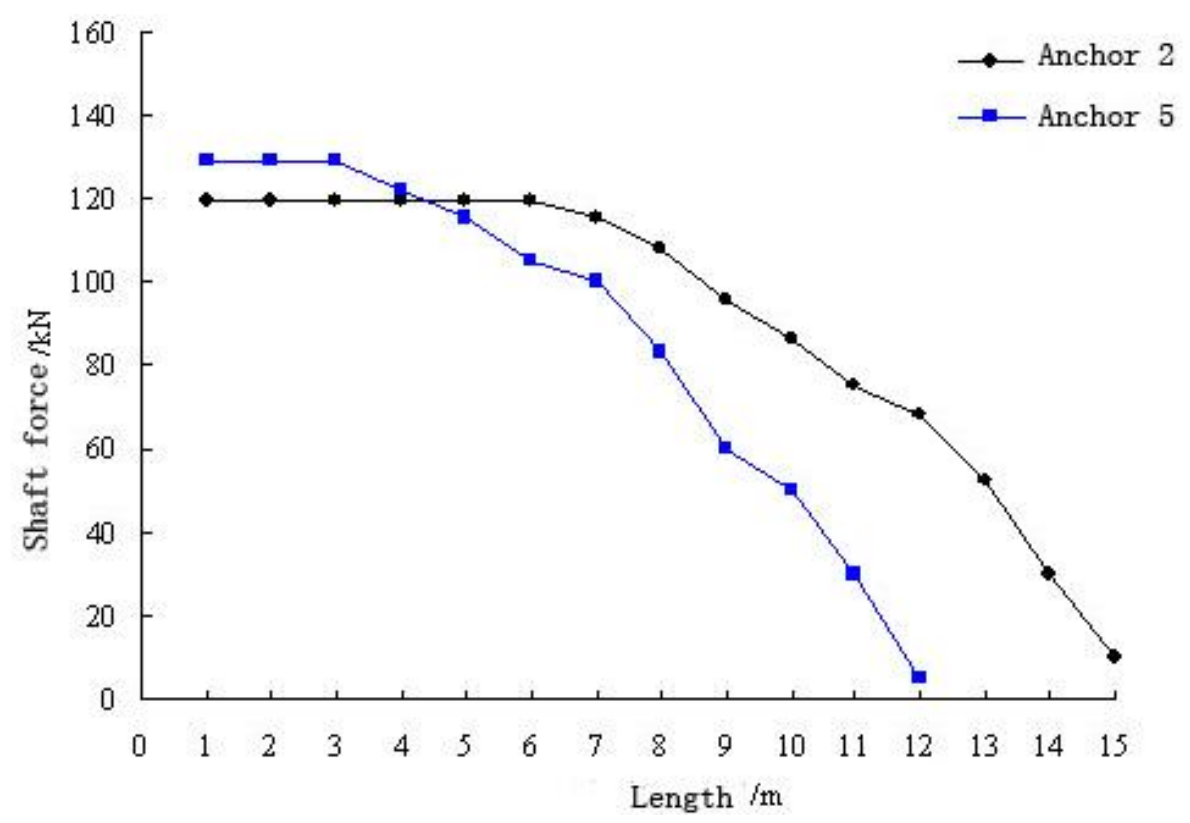

Figure 10. Shaft Force Distribution for Anchor

Based on the Figure 10, the axial force of prestressed achor 2 was $119.6 \mathrm{kN}$, the point of maximum axial force extended to the $6 \mathrm{~m}$ location along the length direction of anchor and then decreased. But for the prestressed achor 5 of lower position, its forcer was the biggest $(128.8 \mathrm{kN})$, the point of this maximum axial force extended to the $3 \mathrm{~m}$ location along the length direction of anchor. Therefore, in order to improve the foundation stability effectively, the value of the next row of prestressed anchor should be increased. Combining Figure 9, the connection line of the maximum axial force of soil nail and anchor were actually the potential failure surface of soil foundation pit, the position change of maximum axial force reflected the trends of internal displacement of excavated soil.

\section{Conclusions}

In this paper, the foundation pit of underground storage in Zheng Zhou City was chose as an example, the simulation model for composite supporting of anchor and soil nail was set by FLAC software, the ideal elastic-plastic constitutive model was selected for soil, the cable unit was selected for the prestressed anchor and soil nailing, based on the interaction between supporting system and soil, the dynamic process for the excavation and support of foundation pit was simulated, the following conclusions were obtained.

(A) For the soil foundation pit, the maximum horizontal displacement generally appeared at the edge of the foundation pit wall surface, the internal horizontal displacement which was away from the side wall was relatively small. The vertical displacement when the excavation is completed decreased with the increment of depth.

(B) The connection line of the maximum axial force of soil nail and anchor were actually the potential failure surface of soil foundation pit, the position change of maximum axial force reflected the trends of internal displacement of excavated soil. 


\section{Acknowledgements}

This work was financially supported by the 2014 special food public welfare research project "research and development of new type storehouse and technical system of ecological grain storage " and Zheng Zhou city science and technology plan projects (academician workstation construction plan) (project number: 131 pysgz205) funding.

\section{References}

[1] XianmingZeng, JiusongHuang and ZuominWang, Editor, Design and Construction of Soil Nailing Support Manual, Chinese Building Industry Press, Beijing (2003)

[2] JinqingJia, Editor, The Prestressed Anchor Flexible Retaining Method for Deep Foundation Pit of The Theory and Practice, Chinese Building Industry Press, Beijing (2006)

[3] MinglongWang, LinhaiWan and ZhiquanHuang, Internal Force Analysis of Soil Nailing Based on FLAC, Journal of Engineering Geology. 3, 14 (2006)

[4] BoLiu, YanhuiHan, The Principle and Application of FLAC, People's Commumication Press, Beijing (2005)

[5] ZongchengWu, LianshengTang and ZhiqiangLiao, Composite Soil Nailing Wall in Deep Foundation Pit, Chinese Journal of Geotechnical Engineering. 28, 1460 (2006)

[6] XiuliDing and QianSheng, Experimental study on Numerical Simulation of Prestressed Anchorage Mechanism, Journal of Rock Mechanics and Engineering. 7,21 (2002)

[7] ZhigangLi, SiqingQin and BingfengZhang, 3D Vertical Soil Nailing Field Test Simulation, Journal of Engineering Geology. 1,12 (2004)

[8] YinmengLu, JunShen and XiantaoZeng, Analysis of Prestressed Anchor Reinforcement of Foundation Pit, Chinese Journal of Geotechnical Engineering. 10,27 (2005)

[9] YiqunTang, ZhendongCui and XinghanWang, A Preliminary Study on The Ground Settlement Caused by Engineering Effect of Dense High-rise Buildings, Northwestern Seismological Journal. 2,29 (2007) 